\title{
Development of a Tellurium Speciation Study Using IC-ICP-MS on Soil Samples Taken from an Area Associated with the Storage, Processing, and Recovery of Electrowaste
}

\author{
Katarzyna Grygoyć (D) and Magdalena Jabłońska-Czapla * (D) \\ Institute of Environmental Engineering Polish Academy of Sciences, M. Sklodowskiej-Curie 34 St., \\ 41-819 Zabrze, Poland; katarzyna.grygoyc@ipispan.edu.pl \\ * Correspondence: magdalena.czapla@ipispan.edu.pl
}

\section{check for}

updates

Citation: Grygoyć, K.;

Jabłońska-Czapla, M. Development of

a Tellurium Speciation Study Using

IC-ICP-MS on Soil Samples Taken

from an Area Associated with the

Storage, Processing, and Recovery of Electrowaste. Molecules 2021, 26, 2651. https://doi.org/10.3390/

molecules26092651

Academic Editor:

Bogusław Buszewski

Received: 19 March 2021

Accepted: 28 April 2021

Published: 30 April 2021

Publisher's Note: MDPI stays neutral with regard to jurisdictional claims in published maps and institutional affiliations.

Copyright: (c) 2021 by the authors. Licensee MDPI, Basel, Switzerland. This article is an open access article distributed under the terms and conditions of the Creative Commons Attribution (CC BY) license (https:// creativecommons.org/licenses/by/ $4.0 /)$.

\begin{abstract}
The optimization and validation of a methodology for determining and extracting inorganic ionic $\mathrm{Te}(\mathrm{VI})$ and $\mathrm{Te}(\mathrm{IV})$ forms in easily-leached fractions of soil by Ion Chromatography-Inductively Coupled Plasma-Mass Spectrometry (IC-ICP-MS) were studied. In this paper, the total concentration of $\mathrm{Te}, \mathrm{pH}$, and red-ox potential were determined. Ions were successfully separated in 4 min on a Hamilton PRPX100 column with $0.002 \mathrm{mg} / \mathrm{kg}$ and $0.004 \mathrm{mg} / \mathrm{kg}$ limits of detection for Te(VI) and $\mathrm{Te}(\mathrm{IV})$, respectively. Soil samples were collected from areas subjected to the influence of an electrowaste processing and sorting plant. Sequential chemical extraction of soils showed that tellurium was bound mainly with sulphides, organic matter, and silicates. Optimization of soil extraction allowed $20 \%$ average extraction efficiency to be obtained, using $100 \mathrm{mM}$ citric acid as the extractant. In the tested soil samples, both tellurium species were present. In most cases, the soils contained a reduced Te form, or the concentrations of both species were similar.
\end{abstract}

Keywords: tellurium; technology critical element; TCE; BCR; speciation; IC-ICP-MS; ICP-MS; fractionation; WEEE; electrowaste

\section{Introduction}

Global trade networks of goods, in which materials move along the value chain of mining, processing, manufacture, use, disposal, collection, and waste management, have increased in complexity in recent years as multiple countries are involved in the life-cycles of products [1]. As a consequence of the growing use of electronic and industrial products, increasing amounts of TCE (Technology Critical Elements) are being released to the environment. The growing supply of TCE to the environment requires an understanding of their mobility, reactivity, and chemical transformations in the environment, which are critically dependent on their chemical form (speciation). The total concentrations of TCE elements are at trace levels, which make their speciation analysis challenging. One of the Less Studied Technology Critical Element (LSTCE) is tellurium, which is increasingly employed in optical magnetic discs, solar panels, and Peltier device production [2].

Tellurium is one of the chalcophile elements that belong to group 16 in the Periodic Table. Its chemical behavior is similar to selenium and in the natural environment can exist in several redox states: telluride (-II), elemental tellurium (0), tellurite (IV) and tellurate (VI) both in organic and inorganic forms. Although chemical properties of tellurium are well known there is few information about its chemical behavior in natural systems. Under ordinary environmental conditions (oxic systems, circumneutral $\mathrm{pH}$, absence of ligands other than those derived from water), the dominant species should be those of Te(IV), while $\mathrm{Te}(\mathrm{VI})$ species will be potent oxidants [3]. Te(IV)/Te(VI) ratio can differ under different environmental and biological conditions but studies in natural systems are lacking due to extremely low Te concentrations in geological, environmental, and biological samples and most of them is focused on developing the research methodology and rather concerns 
the total content of tellurium. Research of Hai-Bo Qin et al. [4] showed that in abandoned mine tailings contaminated soil Te was present as a mixture of $\mathrm{Te}(\mathrm{VI})$ and $\mathrm{Te}(\mathrm{IV})$ species, and Fe(III) hydroxides were the host phases for Te(IV), and Te(VI), but Te(IV) could be also retained by illite. The values for total tellurium in soil and sediments vary in general from less than one ppb to a few ppb $(\mu \mathrm{g} / \mathrm{kg})$ depending on locations and sources of contamination [5]. Te content in some types in soils from USA was in the range 0.02 and $0.69 \mathrm{mg} / \mathrm{kg}$ [6]. Ferri et al. [7] studied tellurium species concentration in Soil NIST SRM 2709 (National Institute of Standards and Technology, Standard Reference Material) and showed that in this material the content of inorganic tellurium species was $50 \% \mathrm{Te}(\mathrm{VI})$ and Te(IV). Harada and Takahashi [8] studied the distribution and speciation of Te between the solid and aqueous phases in synthetic soil. Under oxic conditions Te was mainly associated with iron (III) hydroxides, and Te(IV) and Te(VI) species were both found to inner-sphere complexes.

Tellurium is considered toxic and teratogenic, and there are indications that tellurite, $\mathrm{Te}(\mathrm{IV})$, can be more toxic than tellurate, $\mathrm{Te}(\mathrm{VI})$ [9]. Because of easy phyto- and bioaccumulation, local tellurium pollution can pose a threat [10]. Waste electronic equipment, in the form of electrowaste (e-waste), is often the source of precious metals belonging to TCE $[2,10,11]$. E-waste is increasingly flooding the world, and is one of the fastest growing waste streams in the world in terms of volume and its environmental impact on the planet. Moreover, it has garnered significant popular and academic attention since 2010 [12].

The term speciation is often used to define an analytical procedure conducted to determine and identify chemical species and to measure their distribution in a particular sample or matrix. Chemical speciation can also be seen as the process of identifying and determining specific chemical species to learn about the availability and mobility of metals in the context of understanding their chemical behavior. Speciation defines chemical forms, whereas fractionation classifies analytes or analyte groups in a sample with regard to their physical and chemical properties [13]. The results of toxicological tests demonstrate that specific element forms, rather than the total element content, often have a profound impact on living organisms. For that reason, information about the content of different forms of the element occurrence is more important than knowing the total element content in the sample. Generally, it is believed that elements in ionic forms demonstrate biological activity and toxicity to living organisms. It is necessary to integrate separation and spectroscopic techniques, or combinations of techniques, to measure the ionic element forms [14]. One of the ways tellurium speciation in environmental samples is the use of the solid-phase extraction methods. Compared to hyphenated separation techniques, selective solid-phase extraction methods are interesting alternatives for samples with lower concentrations [15-17].

Hyphenated techniques combining a high resolution chromatographic separation with ultrasensitive element-specific detection by inductively coupled plasma mass spectrometry (ICP-MS) often offer the unique possibility of accessing the information on the identities and concentrations of individual metal species present in environmental samples. Unfortunately, the data on the speciation of TCE in the literature are relatively scarce and essentially limited to $\mathrm{Ge}, \mathrm{Te}, \mathrm{Tl}, \mathrm{Pt}, \mathrm{Pd}, \mathrm{Rh}$, and $\mathrm{Gd}$ [18]. In tellurium speciation, as in the case of other ultra-trace elements, combined techniques are dominant. One such technique is headspace single-drop microextraction (HS-SDME) combined with graphite furnace atomic absorption spectrometry (GFAAS) [19]. Another technique used in tellurium speciation is dispersive liquid-liquid microextraction combined with electrothermal atomic absorption spectrometry (DLLME) [20]. This speciation was based on the selective complex formation of APDC (ammonium pyrrolidine dithiocarbamate) as a chelating agent with $\mathrm{Te}(\mathrm{VI})$. The concentration of $\mathrm{Te}(\mathrm{IV})$ was calculated as the difference between the total tellurium and $\mathrm{Te}(\mathrm{VI})$ concentrations [20]. The best solution is to use techniques that allow simultaneous determination of $\mathrm{Te}(\mathrm{IV})$ and $\mathrm{Te}(\mathrm{VI})$, which allows for calculate a Te mass balance if the total content is measured separately. One such technique is ion chromatography-hydride generation-atomic fluorescence spectrometry (LC-HG-AFS) [21]. Anion-exchange chro- 
matography with complexing agents in the mobile phase, ethylenediaminetetraacetic acid (EDTA) and potassium hydrogen phthalate (KHP), was used for separating Te(VI) and $\mathrm{Te}(\mathrm{IV})$. In the literature, we can find a few examples of tellurium speciation where atomic absorption spectrometry (AAS) or atomic fluorescence spectroscopy (AFS) are used to detect one form of tellurium and the total content of this element [22-26].

The application of hyphenated techniques such as HPLC-ICP-MS or IC-ICP-MS allows for speciation analysis and simultaneous determination of several ionic forms of elements $[27,28]$. So far, this combined technique has not been applied to research on tellurium speciation in soils. Direct determination of tellurium in geological samples by inductively coupled plasma mass spectrometry (ICP-MS) is often complicated by its low abundance, poor analytical sensitivity, and the presence of xenon interferences. Fortunately, accurate results, with low xenon interferences, can be obtained in the majority of matrices using both the ${ }^{125} \mathrm{Te}$ and ${ }^{126} \mathrm{Te}$ isotopes. Thanks to this, it is possible to combine analytical techniques in tellurium speciation studies using ICP-MS, with excellent sensitivity and ultratrace amounts of tellurium detection [29-33], for example $0.56 \mathrm{ng} / \mathrm{L}$ when analyzing $\mathrm{Te}(\mathrm{IV})$ in water [27]. There are very few publications on the speciation of tellurium in soils [8], and in the available literature, many authors have only studied the total content of tellurium in soils, or only one of the species [34].

The study verified and validated the methodology of tellurium extraction as well as simultaneous determination of two tellurium species, $\mathrm{Te}(\mathrm{VI})$ and $\mathrm{Te}(\mathrm{IV})$, in soils from the areas surrounding the Waste Electric and Electronic Equipment (WEEE) processing and sorting plant.

\section{Results and Discussion}

\subsection{Optimization of Tellurium Speciation}

\subsubsection{Elution Optimization}

During the research on separating tellurium ionic forms, the type of column (Hamilton PRP-X100 and Dionex IonPac AS7), concentration of eluents (8-10 mM Na 2 EDTA and 2-6 mM KHP), pH of eluents (in the range of 4.29-4.32), separation temperature $\left(20-30{ }^{\circ} \mathrm{C}\right)$, method of preparation of the standards (water or $0.5 \% \mathrm{HNO}_{3}$ ), and complexing with complexing acids were optimized. $\mathrm{Te}(\mathrm{IV}) / \mathrm{Te}(\mathrm{VI})$ ions were separated with the Hamilton PRP-X100 column $(150 \mathrm{~mm} \times 4.6 \mathrm{~mm}, 5 \mu \mathrm{m})$. The anion exchange column Dionex IonPac AS7 $(250 \mathrm{~mm} \times 4 \mathrm{~mm}, 10 \mu \mathrm{m})$ was tested, but the obtained chromatogram presented wider peaks and stronger tailings of tellurium species (data not shown).

\subsubsection{The Influence of the Complexing Reagents on Tellurium Species Separation}

Even the use of two complexing reagents present in the eluent, such as $\mathrm{Na}_{2}$ EDTA and $\mathrm{KHP}$, did not separate the two forms. It was necessary to use an additional complexing agent so as to keep one of the forms longer on the column. The effect of three acids (citric acid, tartaric acid, oxalic acid) as a factor complexing tellurium ions was tested, analogous to the work of Zheng et al. [35], in which the effect of complexing factors on antimony speciation was studied. $\mathrm{Te}(\mathrm{IV})$ and $\mathrm{Te}(\mathrm{VI})$ at a concentration of $1 \mathrm{~g} / \mathrm{L}$ were diluted with $50 \mathrm{mM}$ solution of citric, tartaric, and oxalic acids. Then, $15 \mathrm{~min}$ were allowed for complexing and the standards were injected into a Hamilton PRP-X100 column using $10 \mathrm{mM} \mathrm{Na} 2$ EDTA and $6 \mathrm{mM} \mathrm{KHP}$ as eluent. In the case of tartaric acid, the Te(IV) peak was wide and tailing, and its intensity was lower compared to the peak when citric acid was used. When oxalic acid was used as the complexing agent, one broad peak was obtained; this reagent was not suitable for Te(IV) complexing. Therefore, each standard and real sample was prepared by the addition of $50 \mathrm{mM}$ citric acid.

\subsubsection{Optimization of the Chromatographic Separation}

Initially, attempts were made to separate $\mathrm{Te}(\mathrm{IV})$ and $\mathrm{Te}(\mathrm{VI})$ using $8 \mathrm{mM}$ EDTA (ethylenediaminetetraacetic acid) and $2 \mathrm{mM} \mathrm{KHP} \mathrm{(potassium} \mathrm{hydrogen} \mathrm{phthalate)} \mathrm{as}$ eluent based on work by Vinas et al. [21]. However, no proper separation was obtained. 
Only the application of $\mathrm{Na}_{2}$ EDTA (disodium ethylenediaminetetraacetic acid) together with KHP allowed the separation of both ionic tellurium forms. Variable concentrations of KHP $(2,4,6 \mathrm{mM})$ and $\mathrm{Na}_{2}$ EDTA $(8$ and $10 \mathrm{mM}$ ) in eluent were tested. The use of higher KHP concentration shortened the retention time of the Te(IV) peak. However, the increase in the KHP concentration did not affect the retention time of the $\mathrm{Te}(\mathrm{VI})$ peak. The use of phthalic acid instead of KHP was also tested along with $10 \mathrm{mM} \mathrm{Na}_{2}$ EDTA $(\mathrm{pH}=4.0)$, but the $\mathrm{Te}(\mathrm{IV})$ peak had a greater retention time, was wider, and exhibited tailing. The most optimal separation conditions were obtained using $10 \mathrm{mM} \mathrm{Na}_{2}$ EDTA together with $6 \mathrm{mM}$ $\mathrm{KHP}$ at $\mathrm{pH}$ in the range of $4.29-4.32$ as eluent.

\subsubsection{Preparation of Standards}

Single-element tellurium standards were prepared daily. The $1 \mathrm{~g} / \mathrm{L} \mathrm{Te}(\mathrm{VI})$ and $100 \mathrm{mg} / \mathrm{L}$ $\mathrm{Te}(\mathrm{IV})$ standards were stored in the fridge at $4{ }^{\circ} \mathrm{C}$. The Te(IV) standard, due to the fact that it contains some $\mathrm{Te}(\mathrm{VI})$, was reduced by the addition of $5 \mathrm{~mL}$ concentrated $\mathrm{HCl}$ at $80{ }^{\circ} \mathrm{C}$ for $30 \mathrm{~min}$ in a water bath. The $1 \mathrm{~g} / \mathrm{L}$ of tellurium(VI) standard was prepared in advance, stored in the fridge at $4{ }^{\circ} \mathrm{C}$, and was stable in a $0.5 \% \mathrm{HNO}_{3}$ solution as tested. Standards were diluted with $50 \mathrm{mM}$ citric acid. The standards of tellurium species were mixed together during calibration preparation. Calibration curves were obtained with measurement of $1 \mu \mathrm{g} / \mathrm{L}, 10 \mu \mathrm{g} / \mathrm{L}$, and $25 \mu \mathrm{g} / \mathrm{L}$ standard solutions for $\mathrm{Te}(\mathrm{IV})$ and $\mathrm{Te}(\mathrm{VI})$, respectively. A linear model of the dependence of concentration of the total number of analyte counts was selected. The coefficient of determination of calibration curves $\mathrm{R}^{2}$ was between 0.9996 and 0.9901 . Figure 1 presents superimposed chromatograms obtained after analyzing Te standard solutions, and Figure 2 shows calibration curves of tellurium species. Selected separation parameters are presented in Table 1. On the other hand, Figure 3 shows the chromatogram of the real soil sample 70 Edel and the chromatogram of standard both tellurium species with a $10 \mu \mathrm{g} / \mathrm{L}$ concentration.

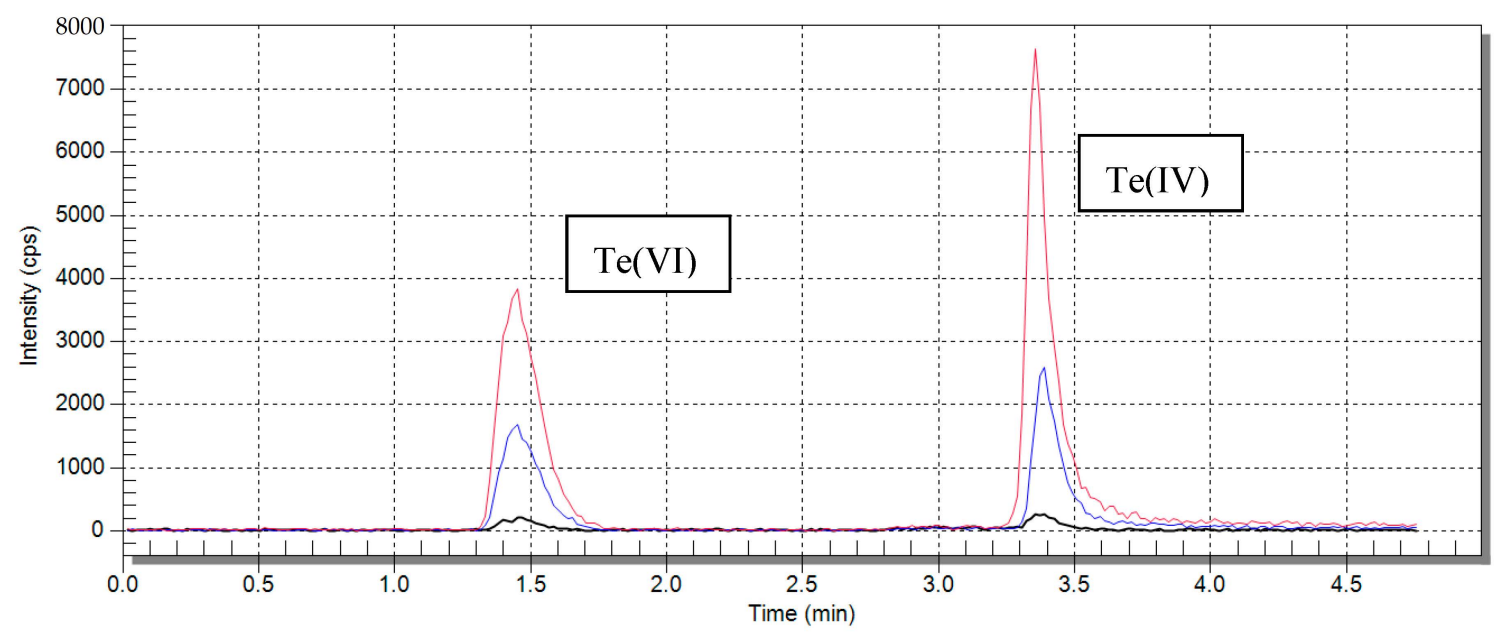

Figure 1. Superimposed chromatograms for tellurium speciation. Calibration curves obtained with measurement of $1 \mu \mathrm{g} / \mathrm{L}$, $10 \mu \mathrm{g} / \mathrm{L}$, and $25 \mu \mathrm{g} / \mathrm{L} \mathrm{Te}(\mathrm{IV})$ and $\mathrm{Te}(\mathrm{VI})$ standard solution. 


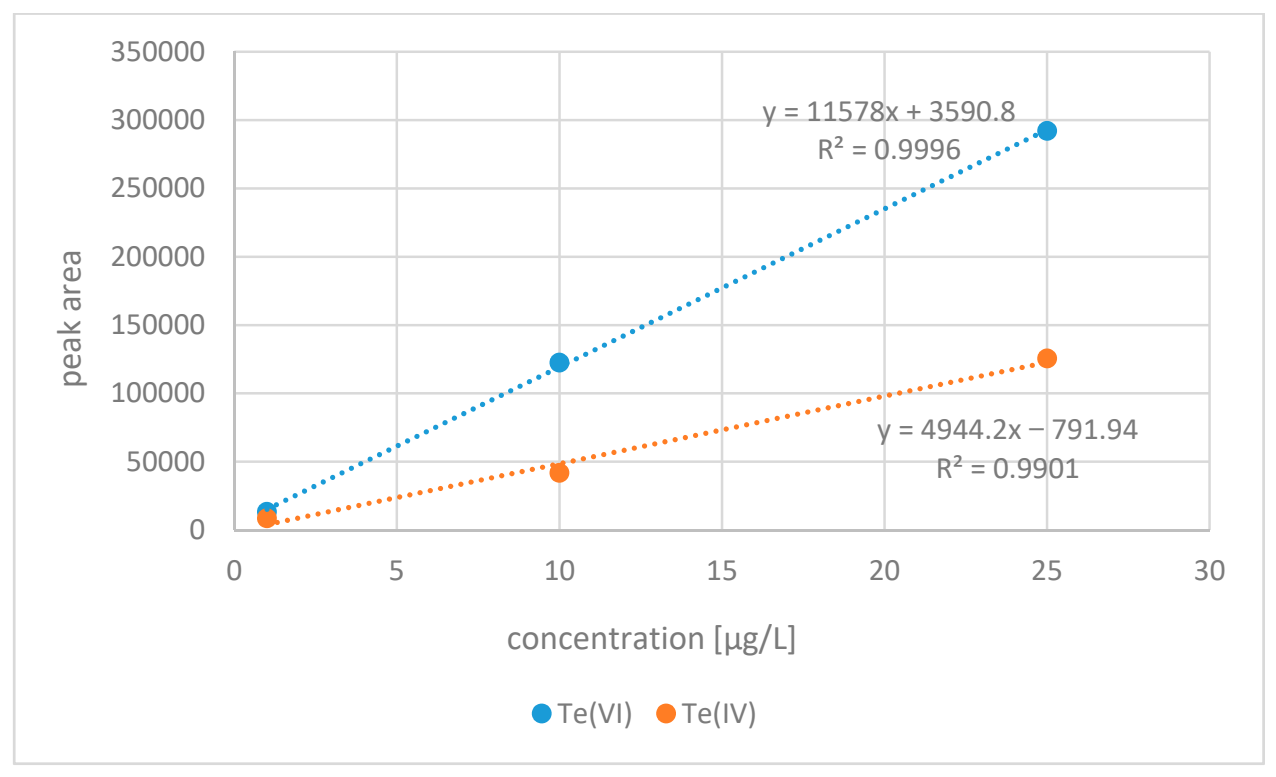

Figure 2. Calibration curves of tellurium species separation.

Table 1. Chromatographic conditions.

\begin{tabular}{cc}
\hline Parameter & Value \\
\hline Separation column & Tellurium \\
\hline Temperature & Hamilton PRP-X100 $4.6 \mathrm{~mm} \times 150 \mathrm{~mm}, 5 \mu \mathrm{m}$ \\
\hline Mobile phase & 30 \\
\hline Elution program & $\begin{array}{c}10 \mathrm{mM} \mathrm{Na} \text { EDTA, 6 mM KHP } \\
\mathrm{pH}=4.29-4.32\end{array}$ \\
\hline Retention time of Te species $[\mathrm{min}]$ & $4 \mathrm{~min}$ \\
\hline Flow rate during analysis $[\mathrm{mL} / \mathrm{min}]$ & $\mathrm{Te}(\mathrm{VI})-1.46$ \\
$\mathrm{Te}(\mathrm{IV})-3.18$ \\
\hline Flow rate during the rinsing $[\mathrm{mL} / \mathrm{min}]$ & 1.2 \\
\hline Volume of sample $[\mu \mathrm{L}]$ & 1.2 \\
\hline
\end{tabular}

\subsubsection{Optimization of Soil Extraction for the IC-ICP-MS Analysis}

The extraction efficiency of soils for the tellurium species content by shaking was insufficient, and it was decided to change the extraction method. It was chosen to use ultrasound to improve the degree of tellurium extraction from the soil. The effect of extraction time on the degree of tellurium leaching after 1,2,3, and $4 \mathrm{~h}$ was investigated.

Figure 4 shows results of tellurium extraction from soils using various solutions (100 mM citric acid, $20 \mathrm{mM} \mathrm{Na} 2$ EDTA, $300 \mathrm{mM}$ ammonium tartrate, and a mixture of $100 \mathrm{mM}$ citric acid with $20 \mathrm{mM} \mathrm{Na}_{2} \mathrm{EDTA} \mathrm{pH}=3.8$ ). The results showed that the best extraction efficiency was obtained by using $100 \mathrm{mM}$ citric acid as an extractant that washes out tellurium from soils within $4 \mathrm{~h}$. The extraction efficiency of the soil samples varied significantly from $9 \%$ for the 110 Edel soil sample, up to $47 \%$ for the 52 Edel sample (Table 2). The extracts of these soils differed significantly, even organoleptically. Forest soil extracts were dark brown in color, and those from urban areas were straw-colored. e.g., soil samples with low extraction efficiency (105 Edel,107 Edel, 110 Edel, 112 Edel) were typically forest soils, containing a lot of organic substances, and their extracts were dark brown in color. On the other hand, the sample extracts, e.g., 52 Edel, 56 Edel, 58 Edel, 61 Edel had a straw color, and the extraction efficiency of these soils was high. 


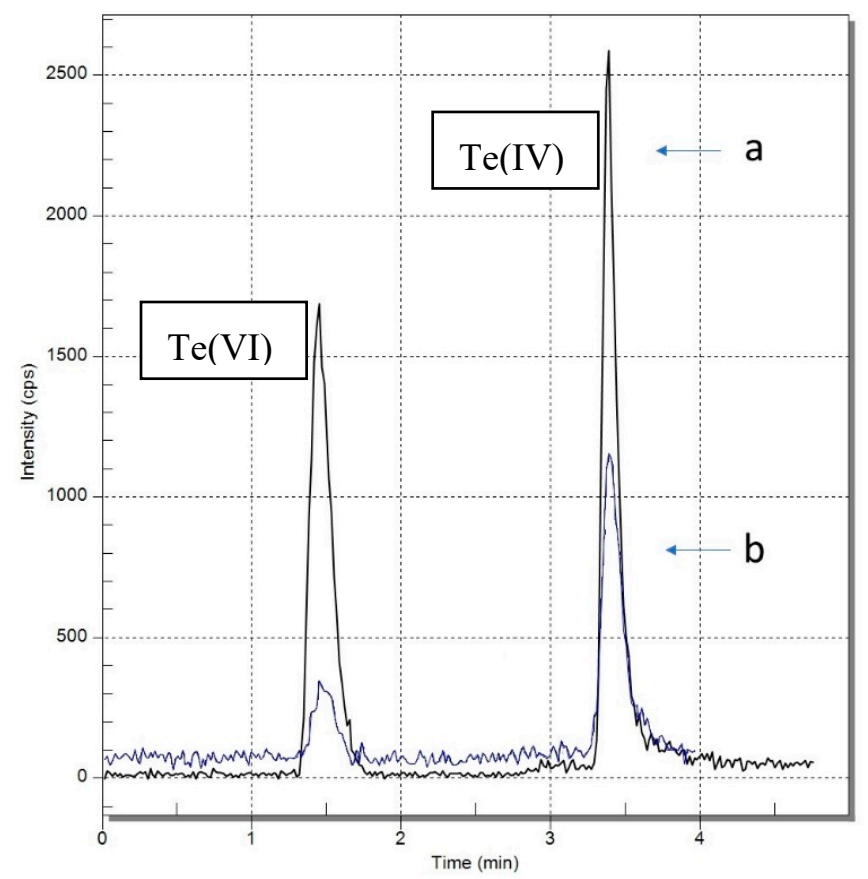

Figure 3. Chromatograms of tellurium species: (a) $10 \mu \mathrm{g} / \mathrm{L} \mathrm{Te}(\mathrm{IV})$ and $\mathrm{Te}(\mathrm{VI})$ standard solution, (b) real soil samples 70 Edel.

12.00

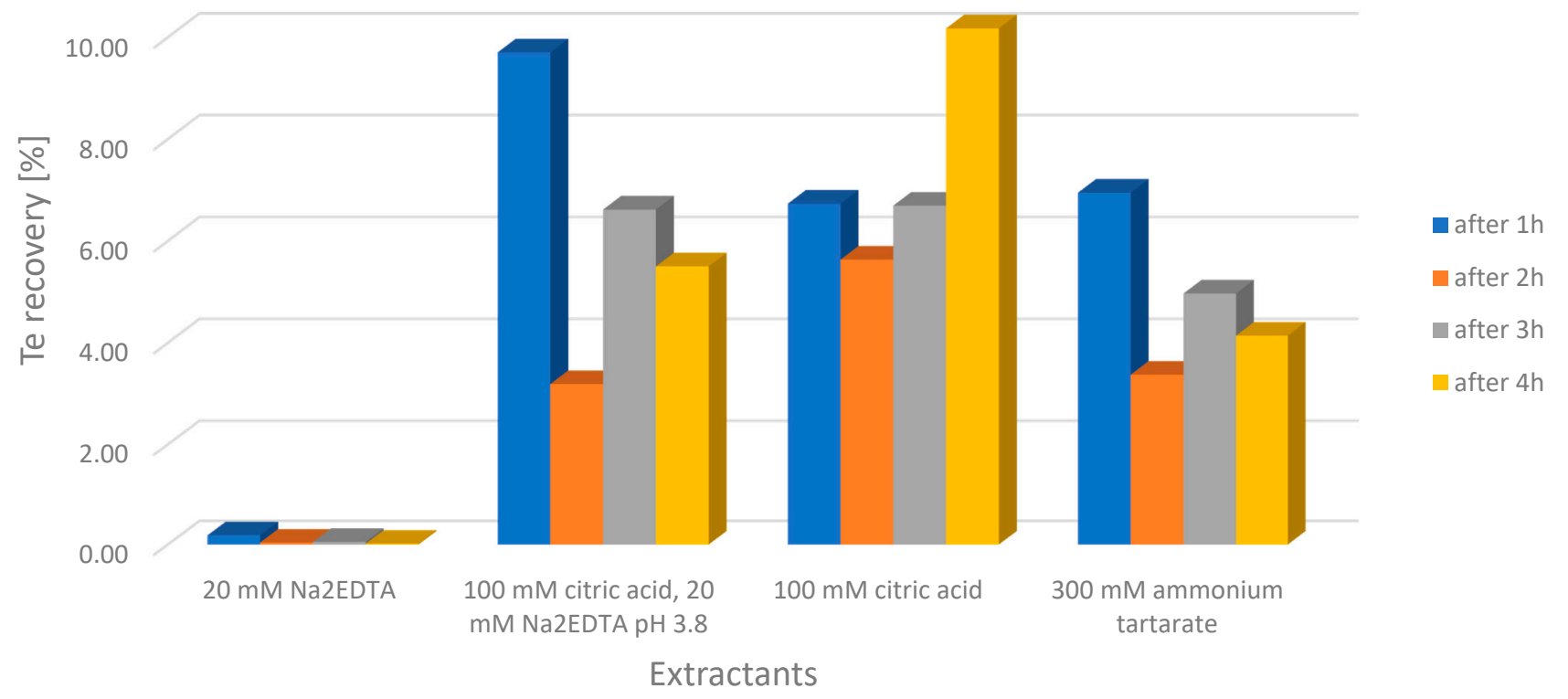

Figure 4. Ultrasound assisted tellurium extraction using various extractants. 
Table 2. Concentration of tellurium and its species in soil.

\begin{tabular}{|c|c|c|c|c|c|c|c|c|c|}
\hline Sample & $\begin{array}{c}\text { Total } \\
\text { Tellurium } \\
\text { Concentra- } \\
\text { tion after } \\
\text { Digestion } \\
{[\mathrm{mg} / \mathrm{kg}]}\end{array}$ & $\begin{array}{c}\text { Total } \\
\text { Tellurium } \\
\text { Concentra- } \\
\text { tion after } \\
\text { Extraction } \\
{[\mathrm{mg} / \mathrm{kg}]}\end{array}$ & $\begin{array}{c}\text { Extraction } \\
\text { Efficiency } \\
{[\%]}\end{array}$ & $\begin{array}{c}\mathrm{Te}(\mathrm{VI}) \\
\text { Concentra- } \\
\text { tion } \\
{[\mathrm{mg} / \mathrm{kg}]}\end{array}$ & $\begin{array}{c}\mathrm{Te}(\mathrm{IV}) \\
\text { Concentra- } \\
\text { tion } \\
{[\mathrm{mg} / \mathrm{kg}]}\end{array}$ & $\begin{array}{l}\text { Sum } \\
\text { Te(IV) and } \\
\text { Te(VI) }\end{array}$ & $\begin{array}{l}\text { pH Value } \\
\text { in } \mathrm{H}_{2} \mathrm{O}\end{array}$ & $\begin{array}{l}\text { pH Value } \\
\text { in } \mathrm{KCl}\end{array}$ & $\begin{array}{c}\mathrm{Eh} \\
{[\mathrm{mV}]}\end{array}$ \\
\hline CRM & 0.42 & 0.043 & 10 & 0.004 & 0.036 & 0.040 & 3.46 & 3.12 & 362.2 \\
\hline 52 Edel & 0.021 & 0.010 & 47 & 0.005 & 0.009 & 0.013 & 3.54 & 3.22 & 387.8 \\
\hline 56 Edel & 0.095 & 0.022 & 24 & 0.010 & 0.006 & 0.016 & 3.82 & 3.54 & 395.2 \\
\hline 58 Edel & 0.083 & 0.025 & 30 & 0.013 & 0.009 & 0.022 & 3.83 & 3.49 & 349.3 \\
\hline 61 Edel & 0.083 & 0.028 & 33 & 0.011 & 0.011 & 0.022 & 3.46 & 3.12 & 412.8 \\
\hline 65 Edel & 0.108 & 0.029 & 27 & 0.020 & 0.007 & 0.027 & 3.85 & 3.59 & 384.5 \\
\hline 70 Edel & 0.129 & 0.016 & 12 & 0.003 & 0.009 & 0.013 & 3.43 & 3.14 & 425.5 \\
\hline 80 Edel & 0.143 & 0.016 & 11 & 0.003 & 0.005 & 0.008 & 3.92 & 3.62 & 384.7 \\
\hline 82 Edel & 0.092 & 0.014 & 16 & 0.009 & 0.008 & 0.017 & 4.09 & 3.58 & 365.8 \\
\hline 97 Edel & 0.105 & 0.022 & 21 & 0.017 & 0.005 & 0.022 & 4.33 & 3.68 & 376.2 \\
\hline 105 Edel & 0.166 & 0.017 & 10 & 0.004 & 0.013 & 0.017 & 3.62 & 3.46 & 375.8 \\
\hline 107 Edel & 0.114 & 0.013 & 11 & 0.002 & 0.005 & 0.007 & 3.45 & 3.15 & 382.4 \\
\hline 110 Edel & 0.124 & 0.011 & 9 & 0.005 & 0.011 & 0.015 & 3.35 & 3.11 & 398.5 \\
\hline 112 Edel & 0.114 & 0.014 & 12 & 0.002 & 0.009 & 0.011 & 3.69 & 3.39 & 396.5 \\
\hline 116 Edel & 0.090 & 0.019 & 21 & $<\mathrm{LOD}$ & 0.017 & 0.017 & 3.42 & 3.14 & 411.1 \\
\hline
\end{tabular}

\subsubsection{Sequential Chemical Extraction}

Sequential chemical extraction of the studied soils showed (Figure 5) that tellurium was mainly bound with organic matter and sulphides (F3A and B), as well as strongly demobilized in the residual fraction. Strong demobilization of tellurium in soils explains the low extraction efficiency of this element with the use of various extractants and the necessity to use ultrasound assistance during tellurium extraction from soils. The results showed that the best extraction efficiency was obtained by using $100 \mathrm{mM}$ citric acid. The use of this extractant (with a low $\mathrm{pH}$ ) allowed for the extraction of tellurium associated with the F2 fraction (metal forms associated with iron and manganese oxides). The remaining extractants, such as $\mathrm{Na}_{2}$ EDTA or ammonium tartarate, had a higher $\mathrm{pH}$ and under these conditions the tellurium was strongly demobilized. Sequential chemical extraction of certified reference material (CRM 73324) showed that tellurium in this soil was mainly associated with the F3 and R fractions. The sum of the tellurium content in the F0 and F1 (mobile) fractions accounted for about 5\% share, while the chemical extraction of CRM with citric acid (during $4 \mathrm{~h}$ ), showed 10\% share of this element extracted from the soil. With the use of citric acid, more tellurium is extracted than what results from the sequential chemical extraction. This is also confirmed by the results of research on real soil samples. In the case of the 58 Edel, 65 Edel or 97 Edel samples, the share of tellurium in the F0 and F1 fractions was higher, and the extraction with citric acid of these soils showed a higher extraction efficiency. 


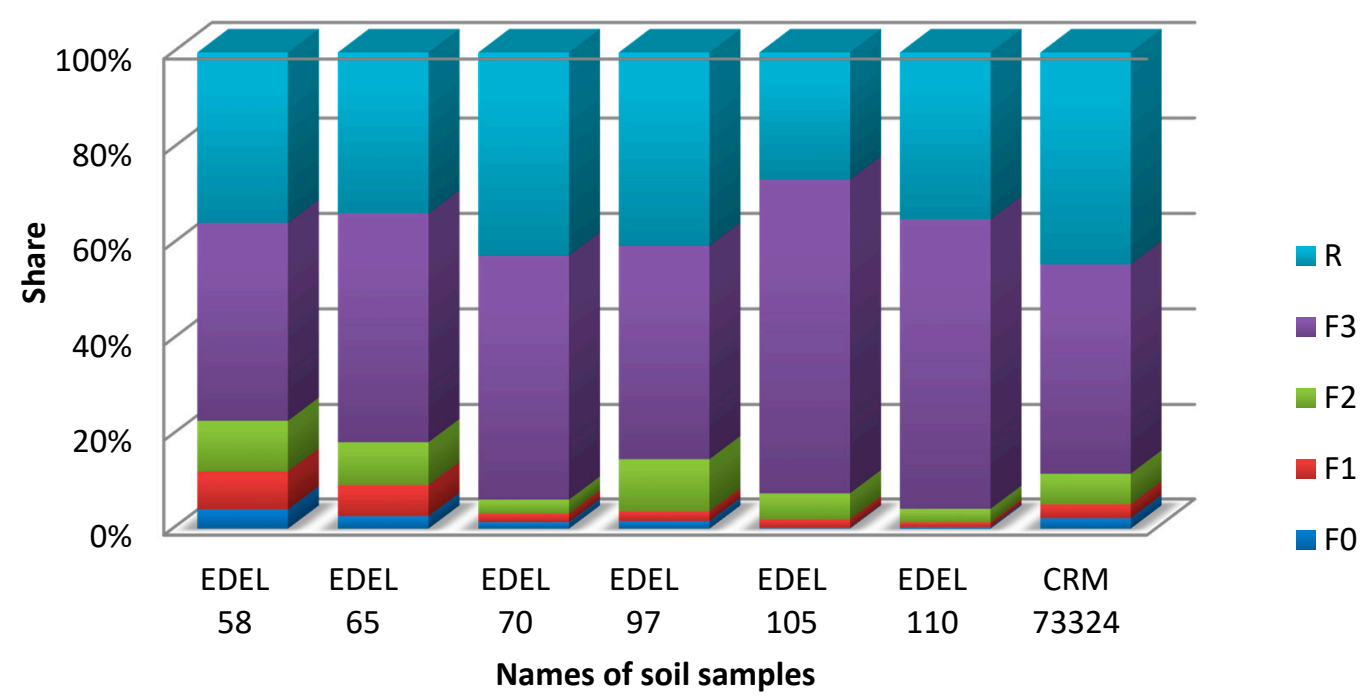

Figure 5. Sequential chemical extraction of tellurium in soil; F0 fraction (metal dissolved in pore water), F1 fraction (metal ion exchange and carbonate); F2 fraction (metal forms associated with iron and manganese oxides), F3 fraction (F3A and B) (metal related to organic matter and sulphides), $\mathrm{R}$ fraction (residual fraction).

\subsubsection{The Matrix Interferences}

Soil type can affect the performance of the method. Soil components, such as organic matter and minerals (clay, sand, silt) in varying proportions, affect the physical, mechanical, chemical and water properties of soils. Matrix effects mainly in recovery, and increase or decrease the response during the analysis due to the presence of substances interfering with the detection of the target compounds. In general the effects of soil parameter on determination of tellurium species are poorly published. The research of Salvia et al. [36] based on the ANCOVA model shows that among other things organic carbon-being one of the main component of SOM (soil organic matter) had a significant impact on recovery. This is also evident in our research. Samples of higher organic matter content showed worse extraction efficiency. While it has been also reported that carbon- based compounds does not cause significant polyatomic interferences at masses ${ }^{126} \mathrm{Te}$ and ${ }^{128} \mathrm{Te}$ [37]. The research of Casiot et al. [38] on soils extract samples exposed to fulvic acid showed that organic matter was not expected to interfere with the species of tellurium in the extract. In our research due to minimalize spectral interferences coming from presence of $\mathrm{Ba}$ and $\mathrm{Xe}{ }^{125} \mathrm{Te}$, ${ }^{126} \mathrm{Te},{ }^{128} \mathrm{Te},{ }^{130} \mathrm{Te}$ isotopes were measured using correction equations $(-0.003404 \times \mathrm{Xe} 129)$ for ${ }^{126} \mathrm{Te},(-0.072617 \times \mathrm{Xe129})$ for ${ }^{128} \mathrm{Te}$, and $(-0.009437 \times \mathrm{Ba} 137-0.154312 \times \mathrm{Xe129})$ for ${ }^{130} \mathrm{Te}$. Toward compensate for matrix effects and drift in analysis of total concentration of elements, a technique with an internal standard was used. Standards, blanks and samples were measured using ${ }^{103} \mathrm{Rh}$ as internal standard. Solution of $10 \mu \mathrm{g} / \mathrm{L} \mathrm{Rh}$ was moved into all solutions and samples on line, by teeing in tubing on peristaltic pump. The average concentration of $\mathrm{Cl}^{-}$and $\mathrm{CO}_{3}{ }^{2-}$ in soil is $0.10 \mathrm{~g} \mathrm{~kg}^{-1}$ and about $0.5 \%$, respectively [39]. Because of the large content of chloride and carbonate ions in soil as well as our earlier experience in speciation analysis study, it was decided to check the influence of $\mathrm{Cl}^{-}$and $\mathrm{CO}_{3}{ }^{2-}$ ions. The matrix effect were tested using $\mathrm{NaCl}$ solution (effect of chlorides on separation) and sodium carbonate solution (effect of carbon addition on separation). The chloride interferences were checked by spiking real samples of soil extracts by $10 \mu \mathrm{g} / \mathrm{L}$ of sodium chloride solution. The same was done in the case of carbonate ions. No effect of chlorides and carbonates on the tellurium speciation analysis was observed.

\subsubsection{Quality Control of the Speciation Analysis}

Limit of detection of tellurium species was determined through measuring a series of standard solutions for two tellurium speciacion forms. The linear model of the concentra- 
tion dependence on total analyte counts was selected. Using the numerous determinations of the calibration curves, they also helped to calculate the limit of detection (LOD) for each tellurium form. The LOD calculation was based on the following dependence:

$$
\mathrm{LOD}=(3.3 \times \mathrm{S}) / \mathrm{b}
$$

where: LOD-limit of detection, S-standard deviation value, b-the slope of the calibration curve.

The standard deviation values were determined as a standard deviation for seven sample solutions spiked with known amount of each tellurium species solutions. Limit of detection tellurium species Te(VI) and Te(VI) was $0.002 \mathrm{mg} / \mathrm{kg}$ and $0.004 \mathrm{mg} / \mathrm{kg}$, respectively. The limits of quantification (LOQ) were expressed as three times the limit of detection value.

Due to the lack of certified reference materials containing both tellurium forms, the methodology for determining tellurium species was checked on the basis of certified reference material, which was extracted like the real soil samples. The obtained results (Table 2) showed that the CRM sample contain mainly a reduced tellurium form, and its recovery was $105 \%$ (the concentration of tellurium from the certificate is $0.4 \pm 0.1 \mathrm{mg} / \mathrm{kg}$ ). Moreover, speciation analysis of the real soil extract (sample 105 Edel) with the addition of $5 \mu \mathrm{g} / \mathrm{L}$ of the mixture of $\mathrm{Te}(\mathrm{VI})$ and $\mathrm{Te}(\mathrm{IV})$ standards was performed. The results showed tellurium content recovery of $111 \%$ for $\mathrm{Te}(\mathrm{VI})$ and $80 \%$ for $\mathrm{Te}(\mathrm{IV})$.

\subsection{Total Tellurium Concentration}

The prepared and validated methodology allowed for the analysis of several soil samples taken from the areas affected by the WEEE processing and sorting plant. The tested soil samples contained small amounts of tellurium. Table 2 presents the concentration of tellurium in studied soils. The total content of tellurium in the samples ranged from $0.02 \mathrm{mg} / \mathrm{kg}$ to $0.42 \mathrm{mg} / \mathrm{kg}$. Thanks to the use of a sensitive analytical method such as ICP-MS, it was possible to quantify such small amounts of tellurium. Sequential chemical extraction (Figure 5) showed that in these soils, tellurium was mainly associated with sulphides and organic matter, and with the silicates (residual fraction). These results confirmed our earlier assumptions. The soils in these areas had a forest character; the extracts were dark in color and contained a lot of humic substances. Sequential chemical extraction (Figure 5) made it possible to explain why the efficiency of tellurium extraction with the use of extractants intended for the speciation analysis was characterized by low efficiency. In the studied soils, tellurium was associated with sulphides and silicates; hence, the extraction of this element with extractants such as citric acid, ammonium tartarate, or $\mathrm{Na}_{2}$ EDTA was characterized by low efficiency.

As reported in the literature, soils tend to be enriched in Te (average around $35 \mu \mathrm{g} / \mathrm{kg}$ ), locally near Te deposits [40]. Volcanoes are one source of environmental Te, where volatile forms of $\mathrm{Te}\left(\mathrm{H}_{2} \mathrm{Te}\right)$ are released through eruptions or hydrothermal activity. For example, Te occurs at 10-1000 mg/kg Te levels in volcanogenic sulfur [41]. While the content of tellurium in soils in the areas associated with the mining of deposits related to $\mathrm{Sb}-\mathrm{As}-\mathrm{Tl}$ ranged from 0.01 to $0.24 \mathrm{mg} / \mathrm{kg}$ [42]. Other authors reported that elevated levels of tellurium (maximum $11 \mathrm{mg} / \mathrm{kg}$ ) are reported in topsoils $(<5 \mathrm{~cm})$ around a long-established nickel refinery at Clydach in the Lower Swansea Valley, UK [43]. The tellurium concentration in Japanese soil ranged from 16.2 to $212 \mathrm{ng} / \mathrm{g}$ or 0.016 to $0.212 \mathrm{mg} / \mathrm{kg}$ [44]. The content of this element in the soil of the Dashuigou tellurium deposit (Sichuan Province, China) was $1.202 \mathrm{mg} / \mathrm{kg}$ [45]. Our preliminary results indicate the influence of sorting and processing electrowaste plant on the increasing tellurium concentration in the topsoil of the surrounding areas. As shown in Figure 6, an increased concentration of tellurium occurred in soil samples located north of the electrowaste processing and sorting plant, which is consistent with the prevailing wind direction in this area (north, north-east). 


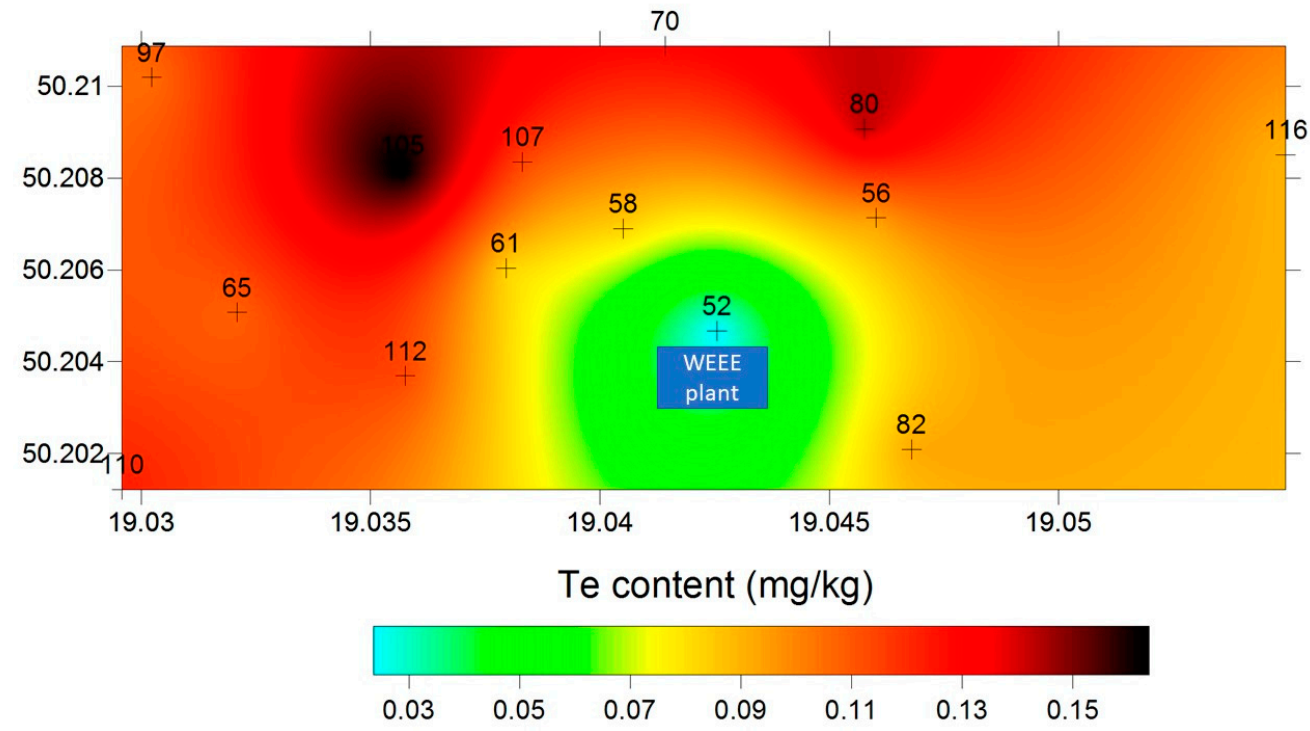

Figure 6. Spatial distribution of the total tellurium content in soil samples in the area surrounding the WEEE processing plant. The map was prepared using Surfer 8 software on the basis of 14 soil samples chosen for Te speciation analysis.

\subsection{Tellurium Speciation}

The study of basic physicochemical parameters (Table 2) showed that the soils in the studied area are slightly acidic. The $\mathrm{pH}$ of soil measured in the water was in the range of $3.35-3.85$, while the $\mathrm{pH}$ of soil measured in $\mathrm{KCl}$ was a minimum of 3.11 to a maximum of 3.68. The redox potential (Eh) of the soils in this area was in the range of $349.3-425.5 \mathrm{mV}$. In the case of tellurium, the +4 and +6 oxidation states have comparable stability. Te(IV) and $\mathrm{Te}(\mathrm{VI})$ forms are stable an coexist in $\mathrm{pH} 4.0$ and charge $\mathrm{E}^{0}(\mathrm{Te}(\mathrm{VI}) / \mathrm{Te}(\mathrm{IV}))=+1.02 \mathrm{~V}$ [17]. The transformations of many soil components and the introduced pollutants are related to redox transformations, which are directly conditioned by the presence of electron acceptors [46]. By determining the redox potential in soil, it is possible to determine its redox state. The ability of the soil to maintain the redox potential Eh at a sufficiently high level is a measure of the soil resistance to reduction processes. The value of $+300 \mathrm{mV}$ proposed by Mortimer is assumed for the boundary between the oxidation and soil reduction conditions. Thus, the measure of soil resistance is the time when the potential drops below the adopted value [47]. The limiting value of redox potential is $+300 \mathrm{mV}$, which corresponds to the reduction of iron (III) to (II) [48]. On this basis, it can be concluded that the soils surrounding the electrowaste treatment plant are characterized by a higher Eh (above $300 \mathrm{mV}$ ) and are oxygenated. Therefore, it is not surprising that the results of the speciation analysis showed that the oxidized tellurium form $\mathrm{Te}(\mathrm{VI})$ appeared in soil samples. The results presented in Table 2 showed that, in the tested soils, the concentration of both tellurium forms was comparable or that the concentration of the reduced form of tellurium quantitatively exceeded the content of $\mathrm{Te}(\mathrm{VI})$. Preliminary studies have shown that the problem is complex and requires in-depth research in this area.

Tellurium is usually present at very low concentrations in environmental samples, which makes it a challenging element to measure in complex matrices. Most tellurium compounds are considered toxic. Except from samples collected close to sources of contamination, tellurium concentrations in soils and sediments are normally at the low ppb $(\mu \mathrm{g} / \mathrm{g})$ level [5]. Te is generally bound by sorption onto clay-sized soil particles rather than in minerals [49]. In particular, a strong association has been observed between $\mathrm{Fe}^{3+}$ oxide minerals and tellurium. $\mathrm{Te}(\mathrm{VI})$ can be incorporated into the structures of $\mathrm{Fe}^{3+}$ oxides, whereas $\mathrm{Te}(\mathrm{IV})$ tends to be bound more weakly to $\mathrm{Fe}^{3+}$ oxides by surface interactions only [4]. However, as our research has shown (Figure 5), in the case of soil samples tested in the area surrounding the WEEE plant, tellurium was mostly associated with F3 (metal 
related to organic matter and sulphides) and $\mathrm{R}$ (residual) fraction. The share of tellurium bound to iron oxides in these soils did not exceed $10 \%$.

\section{Material and Methods}

\subsection{Sampling Area and Soil Preparation}

Samples for this study were taken from the area surrounding the WEEE processing plant, which was located in the Metropolis of Upper Silesia and Zagłębie in Poland. This area is heavily urbanized and is the most industrialized area of Poland. The company collects used devices and components from electrical and electronic devices. Waste is segregated and collected according to the type and stored in containers and big bags on a hard surface. The storage site is covered, which protects the waste from contact with rainfall and prevents the leakage of metal compounds and hazardous substances directly into the soil. In one of the closed halls, manual disassembly of electronic elements and components is carried out, and in another closed hall, the process of "skinning" copper cables is carried out with the use of a cable recycling machine. Soil sampling was performed using a Humax soil sampler to collect undisturbed $30 \mathrm{~cm}$ soil cores (two from each place). Soil samples were separated and subjected to chemical analysis after air drying, averaging, and sieving through a sieve with a mesh size of $0.2 \mu \mathrm{m}$. The basic physicochemical parameters of soils, such as $\mathrm{pH}$ and Eh (redox potential), were collected at fourteen points after the samples were delivered to the laboratory. Eh was measured using the ERPt-111 electrode (Elmetron, Zabrze, Poland) and $\mathrm{pH}$ was measured using the ERH-111 electrode (Elmetron, Poland) [50]. Figure 1 presents spatial distribution of the sampling points in the area surrounding the WEEE processing plant. Table 3 shows the geographic coordinates of the soil sampling points. Figure 6 was prepared using Surfer 8 program on the basis of the samples chosen for Te speciation analysis and a total content as well (in the number of 14). On the map locations of analyzed soil samples were marked. In this area a total of 30 soil cores were collected, from which 66 soil samples were then subjected to geochemical analyzes (non-published data).

Table 3. Geographic coordinates of the soil sampling points.

\begin{tabular}{ccc}
\hline Sample No. & $\begin{array}{c}\mathbf{N} \\
\text { Latitude }\end{array}$ & $\begin{array}{c}\text { E } \\
\text { Longitude }\end{array}$ \\
\hline 52 Edel & 50,204670 & 19,042550 \\
\hline 56 Edel & 50,207130 & 19,046020 \\
\hline 58 Edel & 50,206900 & 19,040510 \\
\hline 61 Edel & 50,206040 & 19,037950 \\
\hline 65 Edel & 50,205070 & 19,032090 \\
\hline 70 Edel & 50,210880 & 19,041430 \\
\hline 80 Edel & 50,209070 & 19,045770 \\
\hline 97 Edel & 50,202090 & 19,046790 \\
\hline 105 Edel & 50,210190 & 19,030230 \\
\hline 107 Edel & 50,208170 & 19,035690 \\
\hline 110 Edel & 50,208350 & 19,038310 \\
\hline 112 Edel & 50,201210 & 19,029580 \\
\hline 116 Edel & 50,203690 & 19,035750 \\
\hline & 50,208510 & 19,054950 \\
\hline
\end{tabular}

\subsection{Apparatus}

The total tellurium content was determined using the Elan 6100 DRC-e ICP-MS spectrometer (Perkin Elmer, Waltham, MA, USA). The ICP-MS apparatus was equipped 
with a standard ICP quartz torch, cross-flow nebulizer, and nickel cones. Table 1 presents operating parameters of the spectrometer. To separate the $\mathrm{Te}(\mathrm{IV})$ and $\mathrm{Te}(\mathrm{VI})$ species, a speciation apparatus set was applied. It consisted of an HPLC chromatograph (Perkin Elmer, USA) equipped with a Series 200LC Peltier oven, Series 200LC autosampler, and Series 200LC gradient pump. The sample from chromatographic column was introduced to ICP-MS by tubing system, automatic diverter and peristaltic pump. The diverter operates as an automatic switching valve to divert undesired portions of the eluate from the HPLC system to waste before the sample enters the ICP-MS. Soil samples were digested in a microwave oven (Microwave 3000, Anton Paar, Austria). Soil extractions were carried out using an ultrasonic cleaner (Sonic 5, Polsonic, Warszawa, Poland), and then the samples were centrifuged using a Beckman Coulter Avanti JXN-26 centrifuge (20,000 rpm, JA-25.50 Fixed-Angle Aluminum Rotor type).

\subsection{Reagents}

The following substances were used for total tellurium content by ICP-MS analysis: tellurium standard for ICP (Sigma-Aldrich, Buchs, Switzerland), Mix 1 (Sigma-Aldrich, Switzerland), and Rhodium standard (Merck, Darmstadt, Germany). Working standard solutions were obtained by appropriate dilution of the stock standard solutions using acidified (suprapur 65\% nitric acid, Merck, Darmstadt, Germany) Milli-Q-Gradient ultrapure deionized water (Millipore, Milli-Q-Gradient ZMQ5V001). Standard stock solution for HPLC speciation of tellurium (IV) $\left(1 \mathrm{~g} \mathrm{Te} \mathrm{L}^{-1}\right)$ and tellurium (VI) (100 $\left.\mathrm{mg} \mathrm{Te} \mathrm{L}^{-1}\right)$ were prepared by dissolving the appropriate amounts of sodium tellurite $\left(\mathrm{Na}_{2} \mathrm{TeO}_{3}\right)($ Aldrich, St. Louis, MO, USA) and potassium tellurate hydrate $\left(\mathrm{K}_{2} \mathrm{TeO}_{4} \times \mathrm{H}_{2} \mathrm{O}\right)$ (Aldrich, USA) in $0.5 \%$ suprapur nitric acid (Merck, Darmstadt, Germany). Moreover 30\% spectrally pure hydrochloric acid (Merck, Germany) was used for reduction of Te(IV) standard. For mobile phase preparation the ethylenediaminetetraacetic acid disodium salt dehydrate (99.0-101.0\%, Sigma-Aldrich, USA) and potassium hydrogen phthalate (KHP) ( $\geq 99.95 \%$, Sigma-Aldrich) were dissolved in water. To check the matrix effects sodium chloride ( $\geq 99,0 \%$, Sigma Aldrich, USA) and sodium carbonate ( $\geq 99,0 \%$, Sigma Aldrich, USA) were used. Citric acid ( $\geq 99.5 \%$, Sigma Aldrich, USA), ammonium tartrate dibasic $(\geq 99.0 \%$, Fluka, Munich, Germany), ethylenediaminetetraacetic acid disodium salt dehydrate (99.0$101.0 \%$, Sigma-Aldrich, USA) were used throughout the extraction studies. $50 \mathrm{mM}$ citric acid ( $\geq 99.5 \%$, Sigma Aldrich, USA) was used for diluting Te(IV) and Te(VI) working solutions. Listed compounds were of analytical grade or higher purity.

\subsection{Sequential Chemical Extraction of Soil}

The BCR (the Institute for Reference Materials and Measurements) sequential chemical extraction helped to determine the tellurium forms in soil and the way in which they were bound. According to this procedure, it is possible to isolate metals associated with the distilled water, 3 main fractions, and an additional residual fraction [51]. Soil samples for BCR analysis were selected based on the quantitative results of tellurium analysis in soils. Soil samples from the top layer with the highest Te content were tested. Conditions for the BCR sequential chemical extraction of tellurium are presented in Table 4. The extraction steps were as follows: Fraction F0 (metal dissolved in pore water); Fraction F1 (metal ion exchange and carbonate, acid soluble, mobile); Fraction F2 (reducible, relates to metal forms associated with iron and manganese oxides, mobile); Fraction F3 (F3A and B) (oxidation, relates to metal forms related to organic matter and sulphides, immobile); Fraction $\mathrm{R}$ (residual fraction, refers to the metal content in the residue after previous extractions, immobile). 
Table 4. Conditions for the BCR sequential chemical extraction of tellurium.

\begin{tabular}{|c|c|c|}
\hline Extraction Rate & Form & Extracting Reagent \\
\hline 0 & Dissolved in pore water & distilled water \\
\hline $\mathrm{F} 1$ & Ion exchange and carbonate & $\begin{array}{c}20 \mathrm{~mL} 0.11 \mathrm{M} \mathrm{CH}_{3} \mathrm{COOH} \\
16 \mathrm{~h} \text {, continuous mixing }\end{array}$ \\
\hline $\mathrm{F} 2$ & Oxide & $\begin{array}{c}20 \mathrm{~mL} 0.1 \mathrm{M} \mathrm{NH}_{2} \mathrm{OH} . \mathrm{HCl} \\
\left(\mathrm{pH} 2 \text {, supplied } \mathrm{HNO}_{3}\right) \\
16 \mathrm{~h} \text {, continuous mixing }\end{array}$ \\
\hline F3 & Organic & $\begin{array}{c}\text { (A) } 10 \mathrm{~mL} \mathrm{H}_{2} \mathrm{O}_{2} 30 \% \mathrm{pH} 2 \\
2 \mathrm{~h} \text { water bath } 85 \pm 2{ }^{\circ} \mathrm{C} \\
10 \mathrm{~mL} \mathrm{H}_{2} \mathrm{O}_{2} 8.8 \mathrm{M} \mathrm{pH}=2 \\
2 \mathrm{~h} \text { water bath } 85 \pm 2{ }^{\circ} \mathrm{C} \\
\text { (B) } 25 \mathrm{~mL} 1 \mathrm{M} \mathrm{NH}_{4} \mathrm{OAc} \mathrm{pH} 2 \\
16 \mathrm{~h} \text { continuous mixing } \\
\left(\mathrm{pH} 2 \text {, supplied } \mathrm{HNO}_{3}\right)\end{array}$ \\
\hline $\mathrm{R}$ & Residual & $\begin{array}{c}6 \mathrm{~mL} \mathrm{HCl}, 2 \mathrm{~mL} \mathrm{HNO}_{3}, 3 \mathrm{~mL} \\
\mathrm{HF} \text { microwave digestion } \\
\text { Anton Paar Microwave } 3000 \text {, } \\
\text { power } 1400 \mathrm{~W} \text {, time } 45 \mathrm{~min} .\end{array}$ \\
\hline
\end{tabular}

\subsection{Determination of the Total Tellurium and Tellurium Species Content}

$0.2 \mathrm{~g}$ of soil samples for the total elements analysis were digested in a microwave oven with $5 \mathrm{~mL}$ of $\mathrm{HNO}_{3}$ (spectral purity, Merck, Germany), $2 \mathrm{~mL}$ of $\mathrm{H}_{2} \mathrm{O}_{2}$, and $3 \mathrm{~mL}$ of HF (spectral purity, Merck, Germany). The digestion program was: $1400 \mathrm{~W}, 35 \mathrm{~min}$. After microwave digestion, samples were diluted to $50 \mathrm{~mL}$ in polypropylene flasks. Afterwards, they were stored in a fridge at $2-5{ }^{0} \mathrm{C}$. Each sample was measured three times using ICPMS. Samples and standards were delivered with a peristaltic pump. The spectrometer was optimized daily with a $10 \mu \mathrm{g} / \mathrm{L}$ solution $(\mathrm{Mg}, \mathrm{Cu}, \mathrm{Rh}, \mathrm{Cd}, \mathrm{In}, \mathrm{Ba}, \mathrm{Ce}, \mathrm{Pb}$, and $\mathrm{U})$ in $1 \% \mathrm{HNO}_{3}$ Elan 6100 Setup/Stab./Masscal. Solution (Perkin Elmer). The concentrations of tellurium were measured with the internal ${ }^{103} \mathrm{Rh}$ standard. Direct determination of tellurium in environmental samples by ICP-MS is often complicated by its low abundance, poor analytical sensitivity, and the presence of Xenon interferences. Therefore ${ }^{125} \mathrm{Te},{ }^{126} \mathrm{Te}$, ${ }^{128} \mathrm{Te},{ }^{130} \mathrm{Te}$ isotopes were measured using correction equations $(-0.003404 \times \mathrm{Xe} 129)$ for ${ }^{126} \mathrm{Te},(-0.072617 \times \mathrm{Xe129})$ for ${ }^{128} \mathrm{Te}$, and $(-0.009437 \times \mathrm{Ba} 137-0.154312 \times \mathrm{Xe129})$ for ${ }^{130} \mathrm{Te}$. The best results were obtained with the ${ }^{126} \mathrm{Te}$ isotope, similar to the work by Filella \& Rodushkin [52]. Standard solutions with Te concentrations from 1 to $25 \mu \mathrm{g} \mathrm{L}{ }^{-1}$ were analyzed to construct a calibration curve with a correlation coefficient of 0.9997 . The matrix effect were tested using $\mathrm{NaCl}$ solution (effect of chlorides on separation) and sodium carbonate solution (effect of carbon addition on separation). No effect of chlorides and carbonates on the tellurium speciation analysis was observed. The relevant information was written in the text. Operating parameters of the ICP-MS spectrometer are shown in Table 5. Optimal separation conditions are presented in Table 1. The most optimal separation conditions were obtained using $10 \mathrm{mM} \mathrm{Na}_{2}$ EDTA together with $6 \mathrm{mM} \mathrm{KHP}$ at $\mathrm{pH}$ in the range of $4.29-4.32$ as eluent. 
Table 5. Operating parameters of the ICP-MS spectrometer.

\begin{tabular}{cc}
\hline Parameter & Value \\
\hline RF power $[\mathrm{W}]$ & ICP-MS \\
\hline Plasma gas flow $[\mathrm{L} / \mathrm{min}]$ & 1125 \\
\hline Nebulizer gas flow $[\mathrm{L} / \mathrm{min}]$ & 15 \\
\hline Auxiliary gas flow $[\mathrm{L} / \mathrm{min}]$ & $0.76-0.82$ \\
\hline Nebulizer type & $1.15-1.16$ \\
\hline Plasma torch & Cross flow \\
\hline Scanning mode & Quartz \\
\hline Dwell time $[\mathrm{ms}]$ & Peak hopping \\
\hline Sweeps $/$ reading & 100 \\
\hline Number of replicates & 20 \\
\hline
\end{tabular}

\subsubsection{Quality Control of Total Tellurium Concentration}

Limits detection of the method of total analysis (LOD) was determined as three times the standard deviation value for the test sample witch were seven spiked samples (5-10 $\times$ noise) taken through all the sample preparation steps before and analyzed. The limits of quantification (LOQ) were expressed as three times the limit of detection value. The limit of detection and quantitation of tellurium was $0.006 \mathrm{mg} / \mathrm{kg}$ and $0.02 \mathrm{mg} / \mathrm{kg}$, respectively. In order to validate the methodology of the total tellurium content, the certified reference material NCS DC 73324 (China National Analysis Center for Tron and Steel, Beijing, China) was used. The digested CRM sample was analyzed for tellurium content, yielding 105\% recovery of tellurium.

\subsubsection{Soil Extraction for IC-ICP-MS Analysis}

Soil samples subjected to speciation analysis were extracted. Extraction of soil samples is not as efficient as microwave digestion, but high temperature and reagents may change the degree of oxidation element species. For this reason, the method of soil extraction was optimized using Certified Reference Material of soil NCS DC 73324 and NCS DC73322 (China National Analysis Center for Tron and Steel, Beijing, China). The development of the extraction methodology included the use of extraction support by shaking and ultrasound. The extraction efficiency of soils for the tellurium species content was checked by shaking $1 \mathrm{~g}$ of the Certified Soil Reference Material (NCS DC73324, NCS DC73322) for $2 \mathrm{~h}$ on a shaker (145 rpm) using $10 \mathrm{~mL}$ of extractants, such as $100 \mathrm{mM}$ citric acid, $20 \mathrm{mM} \mathrm{Na} 2 \mathrm{EDTA}$, $300 \mathrm{mM}$ ammonium tartrate, and water. The degree of tellurium extraction from soils was tested by checking the effect of extraction time and the type of extracting agent at a temperature of $30^{\circ} \mathrm{C}$ using an ultrasonic washer. The effect of extraction time on the degree of tellurium leaching after 1, 2, 3, and $4 \mathrm{~h}$ was investigated. A gradual extraction of the soils was used, in which a fresh extracting agent $(10 \mathrm{~mL})$ was added and, after $1 \mathrm{~h}$ extraction, the sample was centrifuged and fresh extractant was added. For this purpose, $1 \mathrm{~g}$ of a portion of the Certified Reference Material (NCS DC73324) was extracted with various eluents ( $100 \mathrm{mM}$ citric acid, $20 \mathrm{mM} \mathrm{Na}{ }_{2}$ EDTA, $300 \mathrm{mM}$ ammonium tartrate, and a mixture of $100 \mathrm{mM}$ citric acid with $20 \mathrm{mM} \mathrm{Na}_{2}$ EDTA pH =3.8), and then total tellurium content was determined. After extraction, the soil samples were centrifuged using a Beckman Coulter Avanti JXN-26 centrifuge $\left(20,000 \mathrm{rpm}, 8 \mathrm{~min}, 4^{\circ} \mathrm{C}\right)$, and the supernatant was decanted and filtered through a PES syringe filter with a pore diameter of $0.22 \mu \mathrm{m}$.

\section{Conclusion}

The use of combined IC-ICP-MS techniques allowed for the quantification of the tellurium species within $4 \mathrm{~min}$. This required optimization and validation of the extraction 
methodology, separation conditions, and determination of the tellurium species. The optimized methodology allowed interesting research results to be obtained.

According to the literature, tellurium is a naturally occurring element found in its pure state in the Earth's crust in the amount of $0.001-0.01 \mathrm{mg} / \mathrm{kg}$ [9]. However, our results have shown that the concentration of tellurium in soil can be up to 10 times higher and amount to $0.166 \mathrm{mg} / \mathrm{kg}$, despite the fact that $\mathrm{Te}(\mathrm{VI})$ is less thermodynamically stable but more abundant than Te(IV) [18]. Comparable amounts of both tellurium ionic forms were found in soils from the area surrounding the WEEE sorting and processing facility, or the reduced form of this element predominated. The obtained results indicated that research on the influence of the electrowaste processing and sorting plant on the surrounding soil should be continued by testing more soil samples, calculating geochemical coefficients, and examining environmental conditions in greater detail.

The work uses the Surfer 8 program, Microsoft Windows 10 Home edition, Microsoft Office Standard 2016, Elan Version 3.4, Chromera Version 2.0.

Author Contributions: Conceptualization, M.J.-C. and K.G.; methodology, M.J.-C. and K.G.; software, M.J.-C. and K.G.; validation, M.J.-C. and K.G.; formal analysis, M.J.-C. and K.G.; investigation, M.J.C. and K.G.; resources, M.J.-C. and K.G.; data curation, M.J.-C. and K.G.; writing-original draft preparation, M.J.-C. and K.G.; writing-review and editing, M.J.-C. and K.G.; visualization, M.J.-C. and K.G.; supervision, M.J.-C. and K.G.; project administration, M.J.-C. and K.G.; funding acquisition, M.J.-C. and K.G. All authors have read and agreed to the published version of the manuscript.

Funding: This research was funded by the National Science Centre of Poland, grant number UMO2018/ 29/B/ST10/01522.

Institutional Review Board Statement: Not applicable.

Informed Consent Statement: Not applicable.

Data Availability Statement: Not applicable.

Acknowledgments: The research was carried out in the frame of project which received funding from the National Science Centre of Poland on the basis of the decision number UMO-2018/ 29/B/ST10/01522.

Conflicts of Interest: The authors declare no conflict of interest.

Sample Availability: Samples of the compounds are available from the authors.

\section{References}

1. Nuss, P.; Blengini, G.A. Towards better monitoring of technology critical elements in Europe: Coupling of natural and anthropogenic cycles. Sci. Total Environ. 2018, 613-614, 569-578. [CrossRef]

2. Işıldar, A.; Rene, E.R.; van Hullebusch, E.D.; Lens, P.N.L. Electronic waste as a secondary source of critical metals: Management and recovery technologies. Resour. Conserv. Recycl. 2018, 135, 296-312. [CrossRef]

3. Filella, M.; Reimann, C.; Biver, M.; Rodushkin, I.; Rodushkina, K. Tellurium in the environment: Current knowledge and identification of gaps. Environ. Chem. 2019, 16, 215-228. [CrossRef]

4. Qin, H.B.; Takeichi, Y.; Nitani, H.; Terada, Y.; Takahashi, Y. Tellurium Distribution and Speciation in Contaminated Soils from Abandoned Mine Tailings: Comparison with Selenium. Environ. Sci. Technol. 2017, 51, 6027-6035. [CrossRef] [PubMed]

5. Belzile, N.; Chen, Y.W. Tellurium in the environment: A critical review focused on natural waters, soils, sediments and airborne particles. Appl. Geochem. 2015, 63, 83-92. [CrossRef]

6. Govindaraju, K. 1994 compilation of working values and sample description for 383 geostandards. Geostand. Geoanal. Res. 1994, 18, 1-158. [CrossRef]

7. Ferri, T.; Rossi, S.; Sangiorgio, P. Simultaneous determination of the speciation of selenium and tellurium in geological matrices by use of an iron(III)-modified chelating resin and cathodic stripping voltammetry. Anal. Chim. Acta 1998, 361, 113-123. [CrossRef]

8. Harada, T.; Takahashi, Y. Origin of the difference in the distribution behavior of tellurium and selenium in a soil-water system. Geochim. Cosmochim. Acta 2009, 72, 1281-1294. [CrossRef]

9. Kabata-Pendias, A.; Pendias, H. Biogeochemistry of Trace Elements [Biogeochemia pierwiastków śladowych]; PWN: Warszawa, Poland, 1999. (In Polish)

10. Julander, A.; Lundgren, L.; Skare, L.T.; Grander, M.; Palm, B. Formal recycling of e-waste leads to increased exposure to toxic metals: An occupational exposure study from Sweden. Environ. Int. 2014, 73, 243-251. [CrossRef] 
11. Zeng, X.; Wang, F.; Li, J.; Gong, R. A simplified method to evaluate the recycling potential of e-waste. J. Clean. Prod. 2017, 168, 1518-1524. [CrossRef]

12. Kumar, A.; Holuszko, M.; Espinosa, D.C.R. E-Waste: An overview on generation, collection, legislation and recycling practices. Resour. Conserv. Recycl. 2017, 122, 32-42. [CrossRef]

13. Templeton, D.M.; Fujishiro, H. Terminology of elemental speciation-An IUPAC perspective. Coord. Chem. Rev. 2017, 352, 424-431. [CrossRef]

14. Jabłońska-Czapla, M.; Szopa, S.; Grygoyć, K.; Łyko, A.; Michalski, R. Development and validation of HPLC-ICP-MS method for the determination inorganic $\mathrm{Cr}$, As and $\mathrm{Sb}$ speciation forms and its application for Pławniowice reservoir (Poland) water and bottom sediments variability study. Talanta 2014, 120, 475-483. [CrossRef] [PubMed]

15. Ou, X.; Wang, C.; He, M.; Chen, B.; Hu, B. Online simultaneous speciation of ultra-trace inorganic antimony and tellurium in environmental water by polymer monolithic capillary microextraction combined with inductively coupled plasma mass spectrometry. Spectrochim. Acta B 2020, 168, 105854. [CrossRef]

16. Yu, C.; Cai, Q.; Guo, Z.X.; Yang, Z.; Khoo, S.B. Simultaneous speciation of inorganic selenium and tellurium by inductively coupled plasma mass spectrometry following selective solid-phase extraction separation. J. Anal. At. Spectrom. 2004, 19, 410-413. [CrossRef]

17. Yu, C.; Cai, Q.; Guo, Z.X.; Yang, Z.; Khoo, S.B. Speciation analysis of tellurium by solid-phase extraction in the presence of ammonium pyrrolidine dithiocarbamate and inductively coupled plasma mass spectrometry. Anal. Bioanal. Chem. 2003, 376, 236-242. [CrossRef]

18. Wojcieszek, J.; Szpunar, J.; Lobinski, R. Speciation of technologically critical elements in the environment using chromatography with element and molecule specific detection. Trends Anal. Chem. 2018, 104, 42-53. [CrossRef]

19. Garcia-Figueroa, A.; Lavilla, I.; Bendichio, C. Speciation of CdTe quantum dots and Te(IV) following oxidative degradation induced by iodide and headspace single-drop microextraction combined with graphite furnace atomic absorption spectrometry. Spectrochim. Acta B 2019, 158, 105631-105640. [CrossRef]

20. Najafi, N.M.; Tavakoli, H.; Alizadeh, R.; Seidi, S. Speciation and determination of ultra trace amounts of inorganic tellurium in environmental water samples by dispersive liquid-liquid microextraction and electrothermal atomic absorption spectrometry. Anal. Chim. Acta 2010, 670, 18-23. [CrossRef]

21. Viñas, P.; López, I.; Merino-Meroño, B.; Hernández-Córdoba, M. Ion chromatography-hydride generation-atomic fluorescence spectrometry speciation of tellurium. Appl. Organomet. Chem. 2005, 19, 930-934. [CrossRef]

22. Chen, Y.W.; Alzahrani, A.; Deng, T.L.; Belzile, N. Valence properties of tellurium in different chemical systems and its determination in refractory environmental samples using hydride generation-atomic fluorescence spectroscopy. Anal. Chim. Acta 2016, 905, 42-50. [CrossRef]

23. Chen, M.; Wu, L.; Yi, X.; Yang, K.; Xie, H. Tellurium speciation in a bioleaching solution by hydride generation atomic fluorescence spectrometry. Anal. Methods 2017, 9, 3061-3066. [CrossRef]

24. Matusiewicz, H.; Krawczyk, M. Determination of tellurium by hydride generation with in situ trapping flame atomic absorption spectrometry. Spectrochim. Acta B 2007, 62, 309-316. [CrossRef]

25. Pedro, J.; Stripekis, J.; Bonivardi, A.L.; Tudino, M. Surface studies on graphite furnace platforms covered with Pd, Rh and Ir as modifiers in graphite furnace atomic ab- sorption spectrometry of tellurium. Spectrochim. Acta B 2015, 107, 152-158. [CrossRef]

26. Tan, Q.; Pan, Y.; Liu, L.; Shu, S.; Liu, Y. Determination of ultratrace tellurium in water by hydride generation atomic absorption spectrometry using online separation and pre-concentration with nano-TiO2 microcolumn. Microchem. J. 2019, 144, 495-499. [CrossRef]

27. Cornelis, R.; Caruso, J.; Crews, H.; Heumann, K. Handbook of Elemental Speciation: Techniques and methodology; John Wiley\&Sons Ltd.: Chichester, UK, 2003.

28. Kuo, C.Y.; Jiang, S.J. Determination of selenium and tellurium compounds in biological samples by ion chromatography dynamic reaction cell inductively coupled plasma mass spectrometry. J. Chromatogr. A. 2008, 1181, 60-66. [CrossRef]

29. Anan, Y.; Yoshida, M.; Hasegawa, S.; Katai, R.; Tokumoto, M.; Ouerdane, L.; Łobiński, R.; Ogra, Y. Speciation and identification of tellurium-containing metabolites in garlic, Allium sativum. Metallomics 2013, 9, 1215-1224. [CrossRef]

30. Bullock, L.A.; Perez, M.; Armstrong, J.G.; Parnell, J.; Still, J.; Feldmann, J. Selenium and tellurium resources in Kisgruva Proterozoic volcanogenic massive sulphide deposit (Norway). Ore Geol. Rev. 2018, 99, 411-424. [CrossRef]

31. Liu, Y.; He, M.; Chen, B.; Hu, G. Simultaneous speciation of inorganic arsenic, selenium and tellurium in environmental water samples by dispersive liquid liquid microextraction combined with electrothermal vaporization inductively coupled plasma mass spectrometry. Talanta 2015, 142, 213-220. [CrossRef]

32. Meng, P.; Xiong, T.; Wu, Y.; Hu, Y.; Wang, H.; Pang, Y.; Jiang, S.; Han, S.; Huang, P.A. Novel strategy to evaluate the degradation of quantum dots: Identification and quantification of CdTe quantum dots and corresponding ionic species by CZE-ICP- MS Chem. Comm. 2018, 54, 5342-5345. [CrossRef]

33. Su, C.K.; Cheng, T.Y.; Sun, Y.C. Selective chemical vaporization of exogenous tellurium for characterizing the time-dependent biodistribution and dissolution of quantum dots in living rats. J. Anal. At. Spectrom. 2015, 30, 426-434. [CrossRef]

34. Jabłońska-Czapla, M.; Grygoyć, K. Speciation and Fractionation of Less-Studied Technology-Critical Elements (Nb, Ta, Ga, In, Ge, Tl, Te): A Review. Pol. J. Environ. Stud. 2021, 30, 1477-1486. [CrossRef] 
35. Zheng, J.; Iijima, A.; Furuta, N. Complexation effect of antimony compounds with citric acid and its application to the speciation of antimony(III) and antimony(V) using HPLC-ICP-MS. J. Anal. At. Spectrom. 2001, 16, 812-818. [CrossRef]

36. Salvia, M.V.; Cren-Olivé, C.; Vulliet, E. Statistical evaluation of the influence of soil properties on recoveries and matrix effects during the analysis of pharmaceutical compounds and steroids by quick, easy, cheap, effective, rugged and safe extraction followed by liquid chromatography-tandem mass spectrometry. J. Chromatogr. A. 2013, 1315, 53-60. [PubMed]

37. Hu, Z.; Gao, S.; Günther, D.; Hu, S.; Liu, X.; Yuan, Y. Direct Determination of Tellurium in Geological Samples by Inductively Coupled Plasma Mass Spectrometry Using Ethanol as a Matrix Modifier. Appl. Spectrosc. 2006, 60, 781-785. [CrossRef]

38. Casiot, C.; Alonso, M.C.B.; Boisson, J.; Donard, O.F.X.; Potin-Gautier, M. Simultaneous speciation of arsenic, selenium, antimony and tellurium species in waters and soil extracts by capillary electrophoresis and UV detection. Analyst 2008, 123, 2887-2893. [CrossRef]

39. Geilfus, C.M. Chloride in soil: From nutrient to soil pollutant. Environ. Exp. Bot. 2019, 157, 299-309. [CrossRef]

40. Missen, O.P.; Mills, S.J.; Etschmann, B.; Reith, F.; Shuster, J.; Smith, D.J.; Brugger, J. Love is in the Earth: A review of tellurium (bio)geochemistry in surface environments. Earth-Sci. Rev. 2020, 204, 103150. [CrossRef]

41. Yu, M.Z.; Chen, X.G.; Garbe-Schonberg, D.; Ye, Y.; Chen, C.T.A. Volatile chalcophile elements in native sulfur from a submarine hydrothermal; system at Kueishantao, Offshore NE Taiwan. Minerals 2019, 9, 245. [CrossRef]

42. Beceva, K.; Stafilov, T.; Sajn, R.; Tanaselia, C.; Makreski, P. Distribution of chemical elements in soil and stream sediments in the area abandoned Sb-As-Tl Allchar mine, Republic of Macedonia. Environ. Res. 2014, 133, 77-89. [CrossRef]

43. Perkins, W.T. Extreme selenium and tellurium contamination in soils-An eighty year-old industrial legacy surrounding a Ni refinery in the Swansea Valley. Sci. Total Environ. 2011, 412-413, 162-169. [CrossRef] [PubMed]

44. Yang, G.; Zheng, J.; Tagami, K.; Uchida, S. Rapid and sensitive determination of tellurium in soil and plant samples by sector-field inductively coupled plasma mass spectrometry. Talanta 2013, 116, 181-187. [CrossRef] [PubMed]

45. Zhang, Q.; Liu, Y.; He, M.; Bai, M.; Xu, W.; Zhao, C. Ore prospecting model and targets for the Dashuigou tellurium deposit, Sichuan Province, China. Acta Geochim. 2018, 37, 578-591. [CrossRef]

46. Stępniewska, Z.; Ostrowski, J.; Stępniewski, W.; Glinski, J. Classification of redox resistance of Polish arable soils and their spatial characteristics. [Klasyfikacja odporności oksydoredukcyjnej gleb ornych polski i ich przestrzenna charakterystyka]. Water-Environ-Rural. Area 2004, 12, 125-133. (In Polish).

47. Gliński, J.; Duliban, J. Redox potential in soils [Potencjał oksydoredukcyjny w glebach]. Agrophys. Prob. 1972, 3, 1-43. (In Polish).

48. Stępniewska, Z. Oxidation reduction properties of Polish mineral soils [Właściwości oksydoredukcyjne gleb mineralnych Polski]. Agrophys. Prob. 1988, 56, 103. (In Polish).

49. Hayes, S.M.; Ramos, N.A. Surficial geochemistry and bioaccessibility of tellurium in semiarid mine tailigs. Environ. Chem. 2019, 16, 251-265. [CrossRef]

50. ISO 10390: 2005 Soil Quality-Determination of $\mathrm{pH}$. International Organization for Standardization. Publication Date 2005-02. Available online: https://www.iso.org/standard/40879.html (accessed on 20 April 2021).

51. Jeske, A.; Gworek, B. Review of methods for determining the bioavailability and mobility of heavy metals in soils [Przeglad metod oznaczania biodostępności i mobilności metali ciężkich w glebach]. Environ. Protect. Nat. Res. 2011, 49, 209-218. (In Polish).

52. Filella, M.; Rodushkin, I. A concise guide for the determination of less-studied technology-critical elements ( $\mathrm{Nb}, \mathrm{Ta}, \mathrm{Ga}, \mathrm{In}, \mathrm{Ge}, \mathrm{Te})$ by inductively coupled plasma mass spectrometry in environmental samples. Spectrochim. Acta Part B 2018, 141, 80-84. [CrossRef] 